\title{
As percepções dos licenciandos em química sobre a carreira do magistério: um estudo sobre o processo de aprendizagem docente
}

Laudelina Braga

laudelina.braga@ifg.edu.br

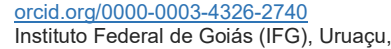
Goiás, Brasil

\begin{abstract}
RESUMO
Esta pesquisa analisa as percepções dos licenciandos de química do Instituto Federal de Goiás - Campus Uruaçu em relação à formação inicial. A investigação pretende refletir sobre a formação inicial de professores e a aprendizagem docente. $O$ foco do estudo será voltado para a influência/relação das percepções dos acadêmicos para com a formação inicial na Licenciatura em Química, bem como as motivações destes em seguirem a profissão docente. Visando a cumprir os objetivos propostos, serão analisadas as falas dos licenciandos em quatro níveis de percepção de análise sistematizados pelo instrumento $F A D$ (Focos da Aprendizagem Docente), os quais são: (1) interesse; (2) conhecimento; (3) reflexão; (4) comunidade. As análises e discussões das percepções dos licenciandos a partir dos FAD indicam que as percepções dos licenciandos em relação à formação inicial contém elementos que influenciam o processo da aprendizagem docente dos professores em formação em um e mais focos constituintes dos FAD em graus diferenciados. Identificamos grande influência dos seguintes focos: interesse pela docência (Foco 1), conhecimento prático da docência (Foco 2) e também reflexão sobre a docência (Foco 3).
\end{abstract}

PALAVRAS-CHAVE: Formação inicial de professores. Ensino de química. Aprendizagem docente. 


\section{INTRODUÇÃO}

Estudos que têm como objeto a formação de professores têm ocupado espaço cada vez maior no debate contemporâneo em prol de um ensino que realmente dê conta de contribuir com a oferta de uma educação pública, gratuita e com qualidade. Nesse sentido, para alcançar essa proposta de educação, a formação de professores tornou-se, nos últimos anos, objeto de destaque.

Questiona-se o modelo de formação, a fragmentação das disciplinas técnicocientíficas com as pedagógicas, ou seja, há uma intensa discussão a favor da teoria e outras tantas a favor da prática, em uma tentativa de se ter um ideal de professor.

Esses estudos apontam, antes de tudo, para a necessidade de se conhecer esse futuro professor, suas opiniões, experiências que o moldaram, ou seja, suas percepções acerca do que é aprender, a sua relação com a futura profissão, o porquê das escolhas, os motivos que levaram a escolher um curso de licenciatura, as (des)motivações encontradas durante as aulas.

Portanto, a partir dessas premissas originou-se a seguinte questão norteadora dessa investigação: Quais são as percepções dos estudantes na formação inicial da Licenciatura em Química no Instituto Federal de Goiás - Câmpus Uruaçu? E qual a relação dessas percepções com sua aprendizagem?

Dessa forma, essa investigação teve como objetivo geral discutir a influência/relação das percepções dos acadêmicos da Licenciatura em Química no Instituto Federal de Goiás - Campus Uruaçu para a formação inicial. Justificou-se a realização dessa investigação embasando-nos em Krug (2005) que destaca que estudos dessa natureza podem oferecer subsídios para modificações no contexto da formação de professores de Química, mais particularmente na compreensão das percepções dos acadêmicos, auxiliando assim na melhoria da qualidade da formação inicial.

A coleta dos dados ocorreu sob a perspectiva da pesquisa qualitativa, utilizando-se da aplicação de um questionário com perguntas abertas para traçar o perfil dos interlocutores e conhecer as concepções, valores e significados do ser professor por meio das rememórias e reflexões sobre experiências vivenciadas no contexto da formação inicial. A investigação das falas dos licenciandos foi feita a partir de categorias de análise pelo instrumento FAD - Focos de Aprendizagem Docente (ARRUDA; PASSOS; FREGOLENTE, 2012).

\section{AS PERCEPÇÕES E A FORMAÇÃO INICIAL: APRENDIZAGEM DOCENTE}

A discussão a respeito das percepções dos licenciandos sobre a futura profissão pode ser considerada fundamental para o estímulo do processo da aprendizagem docente dos licenciandos. Os estudantes nos cursos de formação inicial já trazem consigo saberes experienciais, saberes que foram construídos durante a trajetória de vida, que os influenciam a terem certas percepções acerca do que é ensinar, do que é aprender, como se ensina e como se aprende, ou seja, conhecimentos que devem ser considerados durante as aulas, enquanto espaço de formação (TARDIFF, 2002). 
As instituições responsáveis pela formação inicial deveriam estar dispostas a conhecer esses licenciandos que, mesmo tendo ou não experiências com o exercício do magistério, de certa forma, já trazem esses saberes experienciais que devem ser revistos, refletidos e reelaborados como espaços de reflexão e formação (GONÇALVES; GONÇALVES, 1998).

Dessa maneira, os cursos de formação inicial deveriam levar em conta que esses alunos já trazem saberes construídos ao longo da vida, seja de origem histórico-cultural e familiar, mesmo antes da experiência em sala de aula, (TARDIFF, 2002). Cada licenciando já tem uma ideia e uma imagem do professor que ele pretende ser ou até mesmo do tipo do professor que ele não pretende ser ou atitudes que ele não quer enquanto como professor.

As licenciaturas, para além da finalidade de conferir uma habilitação legal ao exercício profissional da docência, objetivam formar o professor ou, ao menos, colaborar para o exercício de sua atividade docente, mobilizando os conhecimentos da teoria de educação e da didática necessários à compreensão do ensino como realidade social (PIMENTA, 1996). Nesse sentido, a formação inicial deve propiciar situações de aprendizagem em que os licenciandos mobilizem esses saberes e percepções e dialoguem coletivamente, possibilitando a discussão teórico-reflexiva sobre essas questões, problematizando-as, confrontando-as com situações práticas, reelaborando-as e ressignificando-as enquanto saberes sistematizados.

Para isso, os cursos de licenciatura não devem se pautar na fragmentação das disciplinas técnico-científicas e pedagógicas, teoria e prática, primando pela racionalidade técnica ou pela mera instrumentalização, ou seja, inicialmente aprende-se teorias e em seguida, exige-se a aplicação dessas em forma de técnicas e habilidades. Esse modelo formativo valoriza o como fazer, em que as disciplinas de cunho pedagógico se assemelham mais a manuais prescritivos em que o licenciando aprende como proceder nas situações de ensino. Assim sendo, o desvelamento dessas percepções, desde os motivos que justificam a escolha do curso de licenciatura, as expectativas do ingresso e as mudanças dessas concepções resultantes dos estudos, o que eles consideram como ensino e aprendizagem, o que eles entendem o que é ser um bom professor, o que se deve quando se aprende algo, se eles foram estimulados e se pretendem seguir a carreira do magistério.

Vale lembrar que essas percepções aliadas aos investimentos pessoais e profissionais contribuem para a formação dos futuros professores. Ou seja, "o modo de situar-se no mundo, de sua história de vida, [...] do sentido que tem em vida o ser professor", e ainda de como estabelece a sua rede de relações com os colegas, e professores da instituição formadora quanto os professores das instituições em que realiza os estágios (PIMENTA, 1991, p. 83).

\section{FOCOS DA APRENDIZAGEM DOCENTE - FAD}

Com a intensa realização de pesquisas na área de educação com foco na formação de professores surge uma preocupação em torno da análise dos dados. Como analisá-los de forma a compreender melhor o contexto da pesquisa e subsidiar as discussões do objeto de estudo? Nesse sentido, para a investigação da 
pesquisa, uma proposta seria a utilização do instrumento de análise FAD - Focos de Aprendizagem Docente.

Tal discussão foi iniciada e proposta por Arruda, Passos e Fregolente (2012) a partir da analogia aos Focos da Aprendizagem Científica - FAC e apresentados em um dos relatórios do National Research Council, intitulado Learning Science in Informal Environments: People, Places and Pursuits (2009).

Os FAC organizam seis habilidades científicas específicas denominadas strands of science learning que se manifestam em ambientes informais. Quando registrada a ocorrência de tais habilidades, pode-se afirmar que houve aprendizagem científica no ambiente. Essas habilidades foram traduzidas como focos e organizadas na escala de 1 a 6, sendo: 1) Foco do Interesse Científico; 2) do Conhecimento Científico; 3) da Prática Científica; 4) da Reflexão sobre a Ciência; 5) da Comunidade Científica; e, 6) da Identidade Científica (ARRUDA; PASSOS; FREGOLENTE, 2012).

Como se vê, esses focos foram utilizados, inicialmente, para investigar evidências de aprendizado docente em estagiários de Física e Química que atuavam em ambiente de educação informal, e, por isso, houve a necessidade de organizar algumas adaptações nos FAD originais, configurando os FAD'. Essas adaptações são comparativamente apresentadas no Quadro 1:

Quadro1 - Comparativo dos FAD e dos FAD'.

\begin{tabular}{|c|c|}
\hline $\begin{array}{l}\text { Focos da aprendizagem docente } \\
\text { (FAD) }\end{array}$ & $\begin{array}{l}\text { Focos da aprendizagem docente adaptados } \\
\qquad(\text { (FAD') }\end{array}$ \\
\hline $\begin{array}{c}\text { Foco } 1 \text { [interesse pela docência] } \\
\text { O estudante experimenta } \\
\text { interesse, envolvimento emocional, } \\
\text { curiosidade, motivação, } \\
\text { mobilizando-se para exercer e } \\
\text { aprender cada vez mais sobre a } \\
\text { docência. }\end{array}$ & $\begin{array}{l}\text { Foco 1' [interesse pela docência] } \\
\text { O estudante/formador (entrevistado) demonstra } \\
\text { interesse, envolvimento emocional, curiosidade e } \\
\text { motivação para o exercício e a aprendizagem da } \\
\text { docência. Esses fatores podem estar inicialmente } \\
\text { subsumidos ao interesse pelo conteúdo científico } \\
\text { e, posteriormente, desdobrar-se para o interesse } \\
\text { pela docência. Entende-se, portanto, que o gosto } \\
\text { pela docência pode estar de alguma forma } \\
\text { associado ao gosto pelo conteúdo. }\end{array}$ \\
\hline $\begin{array}{l}\text { Foco } 2 \text { [conhecimento prático da } \\
\text { docência] } \\
\text { A partir do conhecimento na ação e } \\
\text { com base na reflexão na ação, o } \\
\text { estudante desenvolve o } \\
\text { conhecimento de casos, um } \\
\text { repertório de experiências } \\
\text { didáticas e pedagógicas que } \\
\text { orientam a sua prática cotidiana in } \\
\text { actu. }\end{array}$ & $\begin{array}{l}\text { Foco 2' [conhecimento prático da docência] } \\
\text { A partir do conhecimento na ação (que poderá } \\
\text { ser adquirido no estágio supervisionado } \\
\text { obrigatório de docência ou na própria atuação } \\
\text { profissional do magistério) e com base na } \\
\text { reflexão na ação, o estudante/formador } \\
\text { (entrevistado) desenvolve o conhecimento de } \\
\text { casos, um repertório de experiências didáticas e } \\
\text { pedagógicas que orientam a sua prática cotidiana } \\
\text { in actu ou que sinalizam orientar novos padrões } \\
\text { de conduta para sua prática (docente) futura. }\end{array}$ \\
\hline Foco 3 [reflexão sobre a docência] & Foco 3’ [reflexão sobre a docência] \\
\hline $\begin{array}{l}\text { Frente a novos problemas } \\
\text { originados de sua prática, os quais } \\
\text { não conseguiu resolver no } \\
\text { momento em que ocorriam, o } \\
\text { futuro professor, com base em } \\
\text { instrumentos teóricos, analisa a }\end{array}$ & $\begin{array}{l}\text { Frente a novos problemas originados de sua } \\
\text { prática, os quais não conseguiu resolver no } \\
\text { momento em que ocorriam, o futuro } \\
\text { professor/formador (entrevistado), com base em } \\
\text { instrumentos teóricos, analisa a situação } \\
\text { sistematicamente, envolvendo-se com a pesquisa }\end{array}$ \\
\hline
\end{tabular}




\begin{tabular}{c}
$\begin{array}{c}\text { Focos da aprendizagem docente } \\
\text { (FAD) }\end{array}$ \\
\hline situação sistematicamente, \\
envolvendo-se com a pesquisa e \\
reflexão a posteriori sobre sua \\
prática e o seu conhecimento \\
acumulado sobre ela, de modo a \\
resolver os problemas inicialmente \\
detectados. Trata-se de
\end{tabular}

desenvolver a dimensão da pesquisa no futuro professor.
Focos da aprendizagem docente adaptados (FAD')

e reflexão a posteriori sobre sua prática e o seu conhecimento acumulado sobre ela, de modo a resolver os problemas inicialmente detectados. Trata-se de desenvolver a dimensão da pesquisa no futuro professor. Contudo, para além dos problemas evidenciados na prática, incluem-se nesse foco todas as reflexões gerais feitas pelos entrevistados acerca da docência e demais componentes desse domínio como: a figura do professor, a aprendizagem escolar, a escola, a vida escolar, entre outros. Assim como no FAD 1', reflexões sobre o conteúdo científico podem também estar de alguma forma associadas à docência (opção pela docência), sendo consideradas neste foco.

Foco 4 [comunidade docente] O estudante participa de atividades desenvolvidas em uma comunidade docente, aprende as práticas e a linguagem da docência com outros professores ou futuros professores, assimilando valores dessa comunidade e desenvolvendo a reflexão coletiva.

Foco 4' [comunidade docente]
O estudante/formador (entrevistado) participa de atividades desenvolvidas por uma comunidade docente (que pode ser a da escola), aprende as práticas e a linguagem da docência com seus professores ou com outros docentes (no caso dos formadores), assimilando valores dessa comunidade e desenvolvendo a reflexão coletiva. Para os estudantes essa participação pode ocorrer durante sua vida escolar, inicialmente.

Foco 5' [identidade docente]

$O$ estudante (entrevistado) pensa sobre si mesmo como um aprendiz da docência e desenvolve uma identidade como alguém que se tornará futuramente um professor de profissão. No caso dos formadores (entrevistados), além da evidenciação de sua identidade com a docência, é considerado seu discurso acerca da identidade com a docência de seus alunos, futuros professores (sua percepção sobre a identidade com a docência em seus alunos).

Isso inclui os meios que utilizam para trabalhar essa questão em sala de aula. Assim como nos FAD 1' e 3', a identidade com a docência pode estar de alguma forma associada ao conteúdo científico e, posteriormente, desdobrar-se para uma identidade com a profissão docente.

Fonte: Adaptado de Lucas, Passos, Arruda (2015).

O estudante pensa sobre si mesmo como um aprendiz da docência e desenvolve uma identidade como alguém que se tornará profissão.
De acordo com os autores Lucas, Passos, Arruda (2015), esses focos representam diversas áreas do conhecimento científico, se desenvolvem e enriquecem mutuamente contribuindo para a aprendizagem de qualquer natureza. A partir de então, conjecturaram sobre os FAC no contexto do processo da aprendizagem docente dos licenciandos e sobre os significados presentes nas falas dos professores em formação, e trouxeram para o campo da pesquisa em 
educação um novo instrumento para análise da aprendizagem docente chamado $F A D$, não mais com seis, e sim, com cinco focos por considerarem teoria e prática (focos 2 e 3 dos FAC) "amalgamadas" (p. 29-32) ou inseparáveis.

Os cinco focos estão dispostos no Quadro 2 e subsidiam as investigações no reconhecimento dos indícios que comprovam a presença da aprendizagem docente.

Quadro 2 - Instrumento para análise da aprendizagem docente

\begin{tabular}{c|c} 
Focos & Aprendizagem docente \\
\hline $\begin{array}{c}\text { Foco 1 } \\
\text { [interesse pela } \\
\text { docência] }\end{array}$ & $\begin{array}{c}\text { O estudante experimenta interesse, envolvimento emocional, } \\
\text { curiosidade, motivação, mobilizando-se para exercer e aprender cada } \\
\text { vez mais sobre a docência. }\end{array}$ \\
\hline $\begin{array}{c}\text { Foco 2 } \\
\text { [conhecimento } \\
\text { prático da } \\
\text { docência] }\end{array}$ & $\begin{array}{c}\text { A partir do conhecimento na ação e com base na reflexão na ação, o } \\
\text { estudante desenvolve o conhecimento de casos, um repertório de } \\
\text { experiências didáticas e pedagógicas que orientam a sua prática } \\
\text { cotidiana in actu. }\end{array}$ \\
\hline $\begin{array}{c}\text { Foco 3 } \\
\text { [reflexão sobre } \\
\text { a docência] }\end{array}$ & $\begin{array}{c}\text { Frente a novos problemas originados de sua prática, os quais não } \\
\text { conseguiu resolver no momento em que ocorriam, o futuro } \\
\text { professor, com base em instrumentos teóricos, analisa a situação } \\
\text { sistematicamente, envolvendo-se com a pesquisa e reflexão a } \\
\text { posteriori sobre sua prática e o seu conhecimento acumulado sobre } \\
\text { ela, de modo a resolver os problemas inicialmente detectados. Trata- } \\
\text { se de desenvolver a dimensão da pesquisa no futuro professor. }\end{array}$ \\
\hline $\begin{array}{c}\text { Foco 4 } 4 \\
\text { [comunidade } \\
\text { docente] }\end{array}$ & $\begin{array}{c}\text { O estudante participa de atividades desenvolvidas em uma } \\
\text { comunidade docente, aprende as práticas e a linguagem da docência } \\
\text { com outros professores ou futuros professores, assimilando valores } \\
\text { dessa comunidade e desenvolvendo a reflexão coletiva. }\end{array}$ \\
\hline $\begin{array}{c}\text { Foco 5 } \\
\text { [identidade } \\
\text { docente] }\end{array}$ & $\begin{array}{c}\text { O estudante pensa sobre si mesmo como um aprendiz da docência e } \\
\text { desenvolve uma identidade como alguém que se tornará } \\
\text { futuramente um professor de profissão. }\end{array}$ \\
\hline
\end{tabular}

Fonte: Adaptado de Arruda, Passos e Fregolente (2012).

Esses eixos de análise (FAD) podem auxiliar no entendimento de que o aprendizado da docência precisa promover nos licenciandos o desenvolvimento de certos interesses, atitudes, conhecimentos e competências, com vistas à carreira de magistério como profissão.

\footnotetext{
Os focos da aprendizagem docente podem ser pensados como grandes objetivos da formação de professores. Ou seja, os programas de formação poderiam almejar que os estudantes despertassem o interesse pela docência, que desenvolvessem o conhecimento prático tão necessário para exercer a profissão, que refletissem sobre o que fazem, que partilhassem de uma comunidade de professores reflexivos e que desenvolvessem uma identidade como docentes (ARRUDA; PASSOS; FREGOLENTE, 2012, p. 44).
}

Destarte, os focos de aprendizagem docente podem ser pensados como categorias que permitem investigar os cursos de licenciaturas. Conhecer as percepções dos licenciandos, analisá-las a partir dos FAD possibilita condições para o trabalho mais significativo nos espaços de formação no sentido de chamar atenção para o exercício teórico e prático da docência, de valorizar além da reflexão da carreira docente, a aprendizagem em comunidade, vivenciando e trocando experiências, aprendendo colaborativamente. 


\section{METODOLOGIA E COLETA DE DADOS}

Para este estudo foi utilizada a pesquisa qualitativa na perspectiva de Bogdan e Biklen (1994), sendo os dados recolhidos e analisados em "[...] sua riqueza, respeitando, tanto quanto possível, a forma em que estes foram registrados ou transcritos" (p. 48). Os dados e informações foram obtidas por questionários com perguntas abertas, revistas e analisadas pelo pesquisador em que o entendimento é o ponto de partida para análise e interpretação.

O questionário é uma "técnica de investigação composta por um número mais ou menos elevado de questões apresentadas por escrito às pessoas, tendo por objetivo o conhecimento de opiniões, crenças, sentimentos, interesses, expectativas, situações vivenciadas, etc." (GIL, 1999, p. 128). A utilização do questionário, não sendo propriamente uma metodologia qualitativa, atende particularmente quando busca investigar e conhecer o que as pessoas sabem, o que gostam ou não gostam e, principalmente, o que pensam. Já Cervo e Bervian (1996) relatam que o questionário representa a forma mais usada para coletar dados, pois possibilita buscar de forma mais objetiva o que realmente se deseja atingir. Consideram ainda o questionário um meio de obter respostas por uma fórmula que o próprio informante preenche. Para eles, pergunta aberta destina-se a obter uma resposta livre.

O questionário, composto com cinco perguntas abertas, foi respondido por dezenove acadêmicos do 5o período do curso de Licenciatura em Química do Instituto Federal de Goiás - Câmpus Uruaçu no segundo semestre de 2015. A escolha dos participantes aconteceu de forma espontânea, em que a disponibilidade deles foi o critério de seleção.

Deste modo, as informações apresentadas e analisadas nesse estudo tiveram como questões norteadoras:

Como você sabe que aprendeu algo?

Para você o que é ser um bom professor?

Você pretende lecionar? Por quê?

Por que você escolheu fazer Licenciatura em Química?

E durante o curso de licenciatura você acha que está sendo estimulado a ser professor? Por quê?

A interpretação das informações coletadas pelo questionário com perguntas abertas foi realizada através da análise de conteúdo, que é definida por Bardin (1977) como um conjunto de técnicas de análise das comunicações visando obter, por procedimentos sistemáticos e objetivos de descrição do conteúdo das mensagens, indicadores (quantitativos ou não) que permitam a inferência de conhecimentos relativos às condições de produção/recepção (variáveis inferidas) destas mensagens.

Godoy $(1995$, p.23), diz que a pesquisa que opta pela análise de conteúdo tem como meta "entender o sentido da comunicação, como se fosse um receptor normal e, principalmente, desviar o olhar, buscando outra significação, outra mensagem, passível de se enxergar por meio ou ao lado da primeira". 
Para Bardin (1977) a utilização da análise de conteúdo prevê três etapas principais:

1a) A pré-análise - que trata do esquema de trabalho, envolve os primeiros contatos com os documentos de análise, a formulação de objetivos, a definição dos procedimentos a serem seguidos e a preparação formal do material;

2a) A exploração do material - que corresponde ao cumprimento das decisões anteriormente tomadas, isto é, a leitura de documentos, a caracterização, entre outros;

3a) O tratamento dos resultados - onde os dados são lapidados, tornando-os significativos, sendo que a interpretação deve ir além dos conteúdos manifestos nos documentos, buscando descobrir o que está por trás do imediatamente aprendido.

Esses procedimentos possibilitaram a análise dos fragmentos das respostas dos licenciandos e permitiram a identificação dos FAD. As respostas serviram como base de investigação de indícios dos focos de aprendizagem docente, portanto, os FAD foram utilizados como categorias de análise. Entretanto, nesse estudo optamos por utilizar como categorias de análise os quatro primeiros a seguir:

Foco 1 - Interesse pela docência,

Foco 2 - Conhecimento prático da docência,

Foco 3 - Reflexão

Foco 4 - Comunidade.

O Foco 5 - Identidade será utilizado em estudos posteriores. Para preservar o nome dos participantes, licenciandos em Química, as respostas foram organizadas por meio de siglas e números: LQ1, LQ2, LQ3, etc. Os dados foram utilizados nos processos de interpretação e análise em que os trechos das falas de cada um dos licenciandos foram categorizados a partir dos FAD assumidos aqui como categorias de análise.

\section{APRESENTAÇÃO E ANÁLISE DOS DADOS}

Pela análise das informações coletadas foram identificados e analisados os seguintes focos de aprendizagem docente nas percepções dos licenciandos da Licenciatura em Química do Instituto Federal de Goiás - Campus Uruaçu:

\section{Foco 1 - Interesse pela docência}

Nessa categoria houve a preocupação em destacar fragmentos das respostas dos licenciandos acerca do interesse, envolvimento emocional e aprendizagem sobre a docência.

Em várias falas dos licenciandos observa-se que muitos entraram no curso por não terem outras opções de formação do nível superior, mas que durante o curso de Licenciatura em Química descobriram outros motivos, como afinidade, interesse em seguir a carreira do magistério, entre outros, como afirma o LQ 2, "na época eu não tinha muitas perspectivas, e me falaram do curso, aí resolvi fazer, 
confesso que no início não tinha muitas pretensões em relação ao curso, mas agora tenho uma visão totalmente diferente, gostei muito do curso".

Outros licenciandos demonstraram que, mesmo tendo poucas opções de cursos superiores, afirmam que têm o desejo de ser professor, apontando características do processo da aprendizagem docente, como observa-se nas falas a seguir:

LQ 1 - Era o que estava disponível no turno da noite e o único curso de uma instituição pública de qualidade em Uruaçu. Pretendo ser professor. Sempre tive este sonho, sei que o professor sozinho não vai mudar o mundo, mas pode ajudar bastante. [...] É saber superar os obstáculos encontrados na sala de aula, assumindo com profissionalismo esta escolha "ser professor".

LQ 6 - Ser um bom professor é ter a consciência de que não se ensina nada, mas fornece condições para o aprendizado, mas o principal para mim, ser um bom professor é querer ser um educador, o qual também se preocupa com o contexto social, emocional e capital cultural de cada aluno e com as transformações na sociedade e na vida do educando. Sem essa preocupação o ensino não teria sentido [...]apesar das diversas dificuldades, acredito que serei um profissional feliz, pois é isso que gosto de fazer, sendo isso o mais importante em qualquer profissão. [...]Sinceramente fazer licenciatura, inicialmente foi uma escola por motivos circunstanciais, tanto por falta de ofertas de outros cursos, como de condições financeiras de fazer outro curso, mas não me arrependo devido o conhecimento adquirido, mas em relação a salário e as condições de trabalho, penso que dificilmente escolheria licenciatura se tivesse outro curso com maior valorização, Mas também não sei se trabalharia com prazer em outro campo sem ser o educacional.

Também observa-se nas falas dos licenciandos um certo envolvimento emocional com a profissão docente, como mostra a fala do LQ 3, "nada melhor que acompanhar a progressão de alguém e saber da sua contribuição para tal processo". Entretanto, alguns licenciandos, não demonstraram interesse, envolvimento emocional em relação à docência, mas apontam uma afinidade com a área técnica, como se observa a seguir:

LQ 4 - Sinceramente por conveniência, ainda que a Química seja uma ciência fantástica e fundamental. Pois por opção mesmo faria outro curso e de preferência bacharelado na área ambiental, por aptidão. De fato, a profissão do docente no Brasil encontra-se em grande parte de forma precária. [...] Um bom professor é aquele que sabe transmitir seu conhecimento para os alunos de forma clara e objetiva, para que os alunos consigam aprender e transmitir o que aprenderam.

LQ 12 - Meu foco nunca foi a própria licenciatura, mas a Química é minha paixão, então considero que em qualquer área da química me sentirei realizada, seja na licenciatura mas preferencialmente seguindo a carreira de pesquisador.

LQ 14 - A licenciatura foi o curso que consegui vaga. Como não queria ficar sem estudar decidi fazer o curso, até conseguir outro curso. Mas acabei permanecendo e vou ficar até o final do curso, mas prefiro as disciplinas de formação técnica.

Outro fator preponderante e decisivo está na relação interesse e conhecimento da profissão, como mostra a fala do LQ 4 "pois aprendi a gostar da profissão e dos processos de ensino-aprendizagem depois que passei a conhecer 
melhor esse trabalho" e também na fala do LQ 12 "Vai além de saber conceitos de uma determinada matéria, um bom professor é aquele que tem uma boa oralidade, paciência, determinação e compreensão". Portanto, o trabalho de professores "é um espaço específico de produção, de transformação e de mobilização de saberes e, portanto, de teorias, de conhecimentos, de saber-fazer específicos ao oficio de professor" (TARDIF, 2002, p. 234)

Os saberes profissionais, conjunto de saberes transmitidos pelas instituições de formação de professores, podem influenciar no interesse pela docência. O professor e o ensino constituem objetos para as ciências humanas e para as ciências da educação e os conhecimentos adquiridos se transformam em saberes que se destinam à formação cientifica dos docentes (TARDIF, 2002, p.36).

Nesta discussão, a formação não se pode pautar no modelo da racionalidade técnica, já que essa não irá considerar as crenças e as representações anteriores sobre ser professor, como argumenta Tardif (2002) sobre o modelo baseado na racionalidade técnica afirmando que esse apresenta dois problemas epistemológicos: primeiro, por ser idealizado de acordo com uma lógica disciplinar e não conforme uma lógica profissional centrada no estudo das tarefas e realidade do trabalho dos professores; e segundo, por tratar os alunos como espíritos virgens, não levando em consideração suas crenças e representações anteriores a respeito do ensino.

É nessa perspectiva que as transformações nas práticas formativas implicam superar o modelo aplicacionista do conhecimento e elevar o nível de conhecimento dos professores, tendo em vista o repertório de saberes sobre o ensino.

Assim sendo, os cursos de licenciaturas ainda enfrentam desafios. Há uma dicotomia entre as disciplinas técnicas e pedagógicas, entre a teoria e o contexto social. O fato é que a formação de professores, no modelo da racionalidade técnica, separada da realidade cultural, social e política, tornam o professor um mero transmissor de conteúdos. A falta de unidade entre as disciplinas pedagógicas e específicas para o ensino de ciências leva o futuro professor para fora da dinâmica do processo educacional, da realidade que se passa na escola (CANDAU, 1994).

\section{Foco 2 - Conhecimento prático da docência}

Esta categoria se deteve ao conhecimento de casos, de repertórios de experiências didáticas e pedagógicas construídas a partir do conhecimento na ação sob a base da reflexão na ação (ARRUDA, PASSOS e FREGOLENTE 2012, p. 40-41).

Os acadêmicos, à medida em que vão cursando as disciplinas de formação específica e as pedagógicas, desenvolvem progressivamente um saber experiencial, e atitudes reflexivas acerca das experiências didático-pedagógicas, e, estas vão orientando as suas práticas, tanto em salas de aulas quanto nas escolas campo em que atuarão como estagiários, como observa-se na fala do LQ 7, "As disciplinas pedagógicas que temos nos dão dicas de como comportar em diversas situações encontradas dentro e fora da sala de aula". 
Nas aulas teórico-práticas, nas atividades práticas, e em cada etapa do estágio, o licenciando vai construindo saberes: planejar aulas com metodologias diferenciadas na expectativa de que todos os alunos aprendam, pelo exemplo das atitudes dos professores formadores, buscar soluções diante dos problemas encontrados em sala de aula no processo de ensino e de aprendizagem, entre outros. E isso ficou notável em várias falas.

LQ 1 - É saber superar os obstáculos encontrados na sala de aula, assumindo com profissionalismo a esta escolha "ser professor". É preciso ainda a compreensão de que os alunos são diferentes e o dever do professor é tentar alcançar a totalidade dos alunos.

LQ 2 - Em todos os momentos os professores nos incentiva a ser professor, até mesmo nas área especificas de química, sempre o exemplo são voltados para situações que podem ocorre em sala de aula.

LQ 3 - Quando é preciso resolver alguma situação, onde é necessário utilizar dos meus conhecimentos cognitivos e consigo resolver o problema em questão. Fazer com que o aluno sinta prazer em aprender algo, e desperta nele o interesse do aprender. E não apenas colocar conteúdos, mas também mostrar sua aplicabilidade.

LQ 4- A partir da prática. Pois pela prática, acredito ser possível diagnosticar se houve aprendizado teórico. Prática, entendo que abrange qualquer aplicação do aprendizado. [...] Um bom professor é aquele que sabe transmitir seu conhecimento para os alunos de forma clara e objetiva, para que os alunos consigam aprender e transmitir o que aprenderam.

Todas essas vivências relacionadas com o conhecimento prático da docência se constituem em aspectos que, como destaca Pimenta (1999), buscam elaborar um pensar/fazer reflexivo:

1) a problematização (a prática pedagógica é mediada pelo questionamento contínuo do que, do por que, do para que e do como fazer);

2) a intencionalidade de procurar respostar às questões (o professor profissional/intelectual sente-se mobilizado a responder às necessidades postas pela realidade);

3) a experimentação metodológica (processo permanente, mesmo que apoiado naquilo que já se faz bem);

4) enfrentamento de situações de ensino complexas (continuamente o professor se depara com a necessidade de tomar diversas e complexas decisões, além de questões endêmicas, como fracasso escolar, indisciplina e desinteresse dos alunos etc.); e

5) tentativas didáticas inovadoras (superação das práticas que não correspondam às suas expectativas e necessidades).

Portanto, o conhecimento prático da docência elege aspectos constituintes de como ser bom professor como expressa a fala do LQ 14 "um bom professor é aquele que consegue levar o aluno a desenvolver suas capacidades. É aquele que utiliza várias formas de metodologias para alcançar todos os alunos. O professor deve sempre está aprimorando, buscando e modificando suas formas de ensinar para possibilitar um bom ensino-aprendizagem". Como afirma Pimenta (1999, p. 29), "a formação é, na verdade, autoformação, uma vez que os professores 
reelaboram os saberes iniciais em confronto com suas experiências práticas, cotidianamente vivenciadas nos contextos escolares".

\section{Foco 3 - Reflexão}

Este foco diz respeito às reflexões sobre a docência realizadas após a ação pedagógica. A reflexão sobre a docência após uma ação ainda é um ponto muito discutido como mostra nos estudos dos seguintes pesquisadores: Pimenta (1991), Gonçalves e Gonçalves (1998), entre outros. Tal fato é decorrente da influência ainda da tendência tradicional e da dicotomia existente entre a prática e a teoria, tão prementes como objeto de discussão no espaço de formação inicial de professores. Quando é possibilitado ao licenciando o espaço de reflexão da ação aliada a uma teoria, insere na sala de aula novas possibilidades de organizar e planejar outras situações de aprendizagem dos licenciandos.

Nesta discussão, Pimenta (1999) explica que é essencial o professor ter consciência da importância de refletir sobre a sua prática pedagógica e sugere que essa reflexão seja num triplo movimento: da reflexão-na-ação, da reflexão-sobrea-ação e da reflexão sobre a reflexão-na-ação. Essas características, diz ela, permitem ao professor condições de analisar e interpretar a sua prática cotidiana, pois, refletindo ele poderá se tornar um profissional autônomo.

Essas atividades devem ocorrer após a realização de uma prática ou de uma aula em que integram conhecimentos teóricos e práticos. Essas devem ser discutidas e refletidas de forma coletiva, possibilitando a todos uma aprendizagem docente colaborativa. Tais indícios são notados em poucas falas dos licenciandos, uma delas, o LQ 7 diz que "as atividades e suas exigências propõe relação ao ato de ensinar, criando um ambiente favorável para idealização de um novo professor", o outro aponta a importância do trabalho em grupo, no sentido de discussão e reflexão, o LQ 8: "saber interagir com os colegas para que as soluções dos problemas seja solucionado em grupo".

Na maioria das falas observa-se a relação do ensino com transmissão do conhecimento desvinculado do espaço para a discussão e reflexão da formação inicial dos professores. E uma das falas que mais representa essa afirmativa, é a do LQ 17, “Um bom professor é aquele que sabe transmitir seu conhecimento para os alunos de forma clara e objetiva, para que os alunos consigam aprender e transmitir o que aprenderam [...] saber transmitir de uma forma simples o conteúdo".

Em outra fala de um licenciando observa-se que a partir dos estágios e experiências, ele reflete o seu papel enquanto professor, aponta aspectos fundamentais na prática pedagógica e a influência dessa na aprendizagem dos alunos e, reafirma a sua escolha enquanto professor de química. aprendi o gosto por ensinar. $O$ ato de contribuir para aprendizagem e a construção do conhecimento do estudante é muito gratificante. [...] Na realidade iniciei o curso por querer estudar e esta era uma das poucas opções na cidade, mas desde os períodos iniciais percebi o gosto pela licenciatura em Química e hoje finalizando o curso pretendo seguir a carreira docente. [...] A questão da carreira do magistério é desestimulante, devido à desvalorização político-social. Porém, o que ensina na graduação é uma preparação e o 
anseio por melhorias na educação e na profissão de professor. E isso pode ser interpretado como estímulo à docência.

A reflexão nesse sentido, reafirma o viés político carregado de conflitos e de lutas, reivindicação por melhores condições de trabalhos e valorização profissional, como reafirma o LQ 4, "acima de tudo ter consciência do trabalho realizado. O bom profissional sabe se está de fato desempenhando o seu melhor potencial profissional. $\mathrm{O}$ indicativo nem sempre é o desempenho do aluno, mas pela consciência o professor se auto avalia", e conforme Pimenta, a prática docente é dotada de "saberes específicos que não são únicos, por não ser composta de um corpo acabado de conhecimentos, já que os problemas da prática profissional docente não são apenas instrumentais mas envolvem situações que exigem decisões complexas, singulares e de conflitos de valores" (PIMENTA, 1999, p. 30).

\section{Foco 4 - Comunidade}

A partir das falas dos licenciandos nos leva a pensar que participar de um grupo de professores geralmente acontece na formação continuada em serviço, por isso, dos dezenove (19) licenciandos que responderam o questionário, apenas dois participavam de uma comunidade que pode ser considerada Comunidade de Prática ${ }^{1}$, o PIBID ${ }^{2}$ - Programa Institucional de Bolsa de Iniciação à Docência.

Um deles, o LQ 16 afirma que "como também participo do PIBID, reflito as minhas práticas, quando desenvolvo aulas práticas nas disciplinas pedagógicas". 0 outro licenciando aponta indícios da relevância que a comunidade assume em sua formação enquanto aprendizagem profissional, como se verifica a seguir:

LQ 3 - Eu sim, pois faço parte de um programa PIBID, onde tive a oportunidade de vivenciar aulas em escolas públicas, reunir com minha orientadora e outros colegas que também participam do PIBID, discutir e refletir as nossas práticas e as práticas observadas nas escolas campo. Sinto o dever de contribuir para melhorar nossa educação. Outra pessoa que não tem o interesse em contribuir, em estar em sala de aula, creio que não se sentiria motivado, levando em consideração as condições de trabalho, o salário, abuso do profissional com excesso de carga horária entre outros motivos.

Para Tardif (2002), a relação dos docentes [ou dos futuros docentes] com os saberes não é restrita a uma função de transmissão de conhecimentos já constituídos. Ele explica que a prática docente integra diferentes saberes e que mantém diferentes relações com eles. Define o saber docente "[...] como um saber plural, formado pelo amálgama, mais ou menos coerente, de saberes oriundos da formação profissional e de saberes disciplinares, curriculares e experienciais" ( $p$. 36).

Pelo o que se observa, pertencer a um determinado grupo relaciona-se como forma potencial de trocas de experiências, vivenciar situações de ensino e de aprendizagem, discutir e refletir diferentes práticas pedagógicas e suas inferências que tem como elemento central a preocupação com a aprendizagem com qualidade de todos os alunos. A prática docente, portanto, é vista como "espaço de produção [coletiva] de competência profissional pelos próprios professores" (TARDIF, 2002, p. 291) 
Entretanto, de uma forma geral os textos respostas dos licenciandos não apresentaram tantas evidências sobre o processo da aprendizagem docente neste foco, que tem como característica essencial a participação em um grupo de professores, ou uma comunidade de prática que desenvolve, eventualmente, reflexões coletivas sobre seu trabalho.

\section{CONSIDERAÇÕES FINAIS}

A partir dos questionários com perguntas abertas foi possível conhecer as percepções e as motivações dos licenciandos em Química em seguir a carreira do magistério. Essas informações e percepções obtidas das respostas dos licenciandos foram analisadas e discutidas tendo como base o instrumento os focos de aprendizagem docente (FAD) proposto por Arruda, Passos e Fregolente em 2012.

Para tal, utilizamos os quatro primeiros focos que são: interesse pela docência, conhecimento prático da docência, reflexão sobre a docência e comunidade docente, como eixos categóricos esperados para uma eficiente formação inicial. 0 quinto foco (identidade profissional) será utilizado em análises posteriores. 0 conhecimento das percepções dos licenciandos em Química do Instituto Federal de Goiás - Câmpus Uruaçu em relação à formação inicial, trouxe vários indícios que podem influenciar significativamente a aprendizagem docente, e por conseguinte, discussão da organização dos cursos de formação inicial.

A partir das análises das percepções, podemos afirmar que as instituições ofertantes dos cursos de licenciatura, ao conhecer e analisar as percepções trazidas e gestadas por cada licenciando, terão melhores condições de traçar e discutir um programa de formação inicial que melhor atenda as demandas da carreira do magistério e de uma educação com mais qualidade e autonomia.

Pelas discussões e reflexões das falas dos licenciandos, há evidências que a formação inicial ocupa um papel preponderante para a construção da aprendizagem docente, porque é nesse período que os licenciandos, além de trazerem, também constroem percepções da profissão iniciando a construção do seu projeto de ser professor. Daí se faz necessário "em todo percurso formativo que envolve a formação de professores, reconhecer que estes são sujeitos do conhecimento, e como tais, possuem saberes e se mobilizados podem contribuir para formação de novas práticas educativas" (TARDIF, 2002, p. 237).

Portanto, as instituições formadoras assumem a responsabilidade com a aprendizagem dos futuros professores, já que possibilitam o movimento em que o licenciando deixa de ser acadêmico e se prepara para ser professor. Conhecendo e discutindo suas percepções a partir dos FAD, torna-se possível que as instituições formadoras repensem os programas de formação inicial, e que realmente considerem, em suas práticas, o interesse pela carreira do magistério, que possibilite aos licenciandos conhecimentos teórico-práticos que deem conta das demandas do "ser professor", ou seja, que de fato contribuam na formação inicial dos futuros docentes.

Apesar dos desafios da profissão perante à desvalorização social, a escolha do curso por falta de opção e a valorização da formação técnica em detrimento da formação pedagógica, nota-se em várias falas desses licenciandos que, no decorrer da formação, há o desenvolvimento do interesse pela docência, o acesso 
aos conhecimentos práticos, a aprendizagem docente mesmo que nos discursos apresentados haja, intrinsecamente, uma certa desvalorização das atividades reflexivas após as práticas e outras de formação. Também observou-se que apenas os licenciandos que participam do PIBID apontaram indícios da aprendizagem colaborativa em forma de comunidade de aprendizagem.

Os saberes na formação dos professores contribuem com a construção da identidade profissional. Segundo Pimenta, essa identidade se constrói a partir da significação social da profissão, da revisão constante destes significados, da revisão das tradições e da reafirmação de práticas consagradas culturalmente, que permanecem significativas (PIMENTA,1999).

Destarte, os cursos de licenciaturas enquanto espaço de formação docente ao valorizar não somente os conhecimentos técnicos e específicos, mas também uma formação mais autônoma e consciente, valoriza paulatinamente habilidades e atitudes crítico-reflexivas sobre a própria carreira do magistério, como afirma Freire (1996, p. 47) "ensinar não é transferir conhecimento, mas criar possibilidades para a sua própria produção ou a sua construção". E para isso é fundamental enfatizar que, no exercício de suas funções e na prática de sua profissão, "os professores desenvolvem saberes específicos baseados também em seu trabalho cotidiano e no conhecimento do seu meio" (TARDIF, 2002, p. 38)

Portanto, entendemos que estudos sobre a aprendizagem docente podem ser uma possibilidade de pesquisa promissora, tendo condições de auxiliar significativamente na elaboração e reformulação de cursos voltados para a formação inicial de professores. 


\title{
The perceptions of chemistry graduates in the teaching profession: a study of the learning process for teachers
}

\begin{abstract}
This research analyzes the perceptions of chemistry graduates of the Federal Institute of Goiás - Campus Uruaçu in relation to initial training. The research aims to reflect on initial teacher training and teacher learning. The focus of the study will be on the influence / relation of the perceptions of the academics to the initial training in the Degree in Chemistry, as well as the motivations of these in following the teaching profession. In order to fulfill the proposed objectives, the students' speeches will be analyzed in four levels of perception of analysis systematized by the instrument FAD (Learning Learning Focus), which are: (1) interest; (2) knowledge; (3) reflection; (4) community. The analyzes and discussions of the perceptions of the graduates from the FAD indicate that the students' perceptions regarding the initial formation contain elements that influence the teacher learning process of the teachers in formation in one and more centers constituent of the FAD in differentiated degrees. We identified a great influence of the following focuses: interest in teaching (Focus 1), practical knowledge of teaching (Focus 2) and reflection on teaching (Focus 3).
\end{abstract}

KEY WORDS: Initial teacher training. Chemistry teaching. Teacher education. 


\section{NOTAS}

1.A ideia de comunidades de prática é apresentada por Lave e Wenger (1991 apud MACHADO; ARRUDA; PASSOS; MAISTRO, 2015) e "representa um modelo mais eficaz de aprendizagem que deixa de ser simples e passa a ser social e, por isso, tal teoria é uma nova forma de socializar conhecimentos".

2. O PIBID - Programa Institucional de Bolsa de Iniciação à Docência - foi criado no ano de 2007 e apresentado pela Fundação Capes (Centro de Aperfeiçoamento de Pessoal de Nível Superior) como possibilidade para articular a escola e a universidade durante a formação de professores, por meio da atuação dos licenciandos em escolas da educação básica da rede pública de ensino, por projetos de pesquisa, ensino e extensão. Para aderirão programa, respondem ao edital da Capes as Instituições de Ensino Superior - IES públicas e privadas com e sem fins lucrativos que oferecem cursos de licenciatura e que cumprem com a entrega de projetos e subprojetos, devidamente compostos para as áreas de conhecimento que desejam programar, por exemplo, Ciências Biológicas, Química e Física (BRASIL, 2007).

\section{REFERÊNCIAS}

ARRUDA, S. M.; PASSOS, M. M.; FREGOLENTE, A. Focos da aprendizagem docente. Alexandria (UFSC), v. 5, p. 25-48, 2012. Disponível em:

<https://periodicos.ufsc.br/index.php/alexandria/article/viewFile/37734/29158. Acesso em: 20 jan. 2016>.

BARDIN, L. Tradução de Luis Antero Neto e Augusto Pinheiro. Análise de conteúdo. Lisboa: Edição 70, 1977.

BOGDAN, R.; BIKLEN, S. Investigação qualitativa em educação: uma introdução à teoria e aos métodos. Porto: Porto Editora, 1994.

BRASIL. Ministério da Educação. Seleção pública de propostas de projetos de iniciação à docência voltados ao Programa Institucional de Bolsa de Iniciação à Docência (PIBID). Edital 001 MEC/CAPES/FNDE. 12 dez. 2007.

CANDAU, V. M. (Org.). Rumo a uma nova didática. Petrópolis: Vozes, 1994.

FREIRE, P. Pedagogia da autonomia: saberes necessários à prática educativa. 16 ed: São Paulo, Paz e Terra, 2000.

GIL, Antônio Carlos. Métodos e técnicas de pesquisa social. 5. ed. São Paulo: Atlas, 1999. 
<http://www.scielo.br/scielo.php?script=sci_arttext\&pid=S0034-

75901995000300004>. Acesso em: 9 jan. 2016.

GONÇALVES, T. V. e GONÇALVES, T. O. Reflexões sobre uma prática docente situada: buscando novas perspectivas para a formação de professores. In: GERALDI, C. M. G.; FIORENTINI, D.; PEREIRA, E. M. A. (Orgs.) Cartografia do Trabalho Docente: professor (a) pesquisador (a). Mercado das Letras: Campinas, SP, 1998.

KRUG, H.N. As contribuições da disciplina de Didática para a formação do licenciado em Educação Física da UFSM: um estudo de caso fenomenológico. In: SEMINÁRIO INTERNACIONAL DE EDUCAÇÃO NO MERCOSUL, IX, 2005, Cruz Alta. Anais -Resumos, Cruz Alta: UNICRUZ, 2005. p.35. Disponível em: <http://www.unicruz.edu.br/seminario/artigos/saude/-.pdf>. Acesso em: $24 \mathrm{fev}$. 2016.

LUCAS, L. B.; PASSOS, M. M.; ARRUDA, S. M. Os focos da aprendizagem docente (FAD) como valores gerais para a formação inicial de professores de Biologia. Disponível em: <http://www.if.ufrgs.br/ienci/artigos/Artigo_ID381/v20_n1_a2015.pdf>. Acesso em: 3 fev. 2016.

MACHADO, E. S.; ARRUDA, S.M.; PASSOS, M. M.; MAISTRO, V. I. A. Comunidades de Prática e aprendizagem docente no ambiente informal do PIBID Ciências. Revista Brasileira de Ensino de Ciência e Tecnologia. v.8, p. 71-86, 2015. Disponível em: <https://periodicos.utfpr.edu.br/rbect/article/view/2973>. Acesso em: 03 mar. 2016.

NATIONAL RESEARCH COUNCIL. Learning science in informal environments: people, places, and pursuits. Committee on learning science in informal environments, national research council of the national academies. Washington, DC: The National Academies Press, 2009. Disponível em:

<http://www.nap.edu/catalog/12190.html>. Acesso em: 10 mar. 2016.

PIMENTA, S. G. Saberes pedagógicos e atividades docentes. 4. ed. São Paulo: Cortez, 1991.

(org.) Pedagogia, ciência da Educação? São Paulo: Cortez, 1996.

, (Org.). Saberes pedagógicos e atividade docente. São Paulo: Cortes, 1999. 
Recebido: 30 jul. 2017

Aprovado: 10 jan. 2018

DOI: $10.3895 /$ actio.v3n1.6836

Como citar:

BRAGA, L. As percepções dos licenciandos em química sobre a carreira do magistério: um estudo sobre o processo de aprendizagem docente. ACTIO, Curitiba, v. 2, n. 3, p. 37-55, jan./abri. 2018. Disponível em: $<$ https://periodicos.utfpr.edu.br/actio>. Acesso em: XXX

Correspondência:

Laudelina Braga

Rua Oldrado Silva Rocha, n. 13, Centro, Uruaçu, Goiás, Brasil.

Direito autoral: Este artigo está licenciado sob os termos da Licença Creative Commons-Atribuição 4.0

Internacional.

(c) (1) 